\title{
Raising the bar for market authorisation of new drugs
} Huseyin Naci and colleagues find that raising evidence standards for market entry of new drugs could have numerous benefits, including providing incentives for development in therapeutic areas with few treatment options

\author{
Huseyin Naci researcher ${ }^{1}$, Jonathan Cylus research fellow ${ }^{12}$, Sotiris Vandoros research fellow ${ }^{1}$, \\ Azusa Sato researcher ${ }^{1}$, Kumar Perampaladas technical analyst ${ }^{3}$
}

'LSE Health, London School of Economics and Political Science, London, UK; ${ }^{2}$ European Observatory on Health Systems and Policies, London, UK; ${ }^{3}$ National Institute for Health and Clinical Excellence, London, UK

Calls are increasing for manufacturers to provide evidence of comparative efficacy of new drugs at the time of regulatory approval. ${ }^{1}$ However, drug manufacturers maintain that doing so would create unrealistically high barriers for market entry and deter innovation. At a time of a perceived productivity crisis in the drug industry, many claim that stricter market authorisation regulation will be detrimental to the development of new drugs. ${ }^{2}$ We review the historical effect of regulating market authorisation and examine the benefits and risks of raising evidence standards by requiring evidence of non-inferiority for market entry.

\section{What's the hype?}

Various components of drug development, including experimentation, evidence generation, and marketing are already subject to regulation. However, there is interest in expanding the remit of regulatory agencies in Europe and the United States in order to make drug manufacturers more accountable and market authorisation more stringent. ${ }^{3}$ Recent proposals include making the raw data collected in pivotal randomised controlled trials of new drugs publicly available and developing a framework for independent appraisal of evidence.

One particularly important aspect is the standards of evidence for marketing authorisation. ${ }^{4}$ Currently, each new product is evaluated on its own merit, without being assessed against other available treatments. As a result, many drugs are approved on the basis of placebo controlled trials without showing their equivalence, non-inferiority, or superiority to existing alternatives. There are proposals in the United States and Europe to require evidence on comparative efficacy at the time of licensing. ${ }^{15}$ This is because the current regulatory environment crowds the marketplace with products that offer marginal, if any, improvements in therapeutic value over existing options. ${ }^{67}$ With an ever increasing number of seemingly similar drugs for a given condition, prescribers do not have adequate evidence on the comparative clinical effect and safety to determine the best drug option. ${ }^{8}$

Yet manufacturers have expressed concerns about being required to provide comparative evidence at the time of marketing authorisation. Some argue that existing experimental designs-such as active-comparator trials-are expensive and take a long time to complete. ${ }^{9}$ Delays in launching new products are also said to be costly, as companies lose exclusivity periods and receive potentially lower returns to research and development; this lowered profit expectation, in turn, discourages future investment. ${ }^{10}$ Manufacturers maintain that regulation requiring them to show that their products provide added value would also discourage investment and hinder the development of new drugs. ${ }^{11}$ In a recent survey, $64 \%$ of respondents from these sectors stated that demonstrating that their products have added value, whether clinical or economic, is a major challenge. ${ }^{12}$

\section{Regulatory environment}

The market for pharmaceutical products is highly regulated compared with that of other sectors, with regulators given the power to restrict products from entering the market.

Manufacturers are prohibited from marketing new drugs before they are licensed by the Food and Drug Administration (FDA) in the United States or the European Medicines Agency (EMA) in Europe.

The defining piece of legislation that has had a lasting effect on the evidence standards for pharmaceutical market access in the United States is the Kefauver-Harris Drug Amendments of 1962, which mandated that manufacturers establish proof of efficacy and safety through recognised "well-controlled studies." 13 These amendments formally required manufacturers to establish rules 
of consent, good manufacturing practices, processes for reporting adverse events, and accurate labelling of new products. The amendments were partly a response to the thalidomide controversy-when a drug marketed in Europe to treat the symptoms of morning sickness caused birth defects in thousands of babies. Since Kefauver-Harris, there have been very few legislative developments in the United States. ${ }^{14}$

In Europe, there has also been no formal expansion of regulatory legislation on evidence standards since the EMA's inception in 1996. European regulatory standards, and in particular evidence requirements for marketing approvals, largely parallel those of the United States. Although there is no legal requirement to provide comparative evidence, the EMA is increasingly encouraging its submission. The EMA's Committee for Medicinal Products for Human Use recently stated it was in favour of three arm non-inferiority trials including the experimental drug, placebo, and active control when the use of placebo is deemed ethical and one or more established medicines are available. ${ }^{15}$ EMA also rewards manufacturers with an extended (11 year) marketing protection period if they can demonstrate that their product offers improved efficacy or safety over existing treatments.

In both the United States and Europe, while submission of comparative evidence is encouraged, regulatory agencies have been reluctant to set comparative assessments as the default evidence standard for market approval, although there have been renewed calls to impose stricter regulation on latecomer products that have questionable therapeutic value.

\section{Health of pharmaceutical innovation}

Many have suggested that the pharmaceutical industry as a whole is suffering from a productivity crisis. ${ }^{17}$ Defining innovation in the pharmaceutical sector remains controversial. One commonly used metric by which to measure innovation is the number of new molecular entities entering the marketplace. ${ }^{13}$ The figure $\Downarrow$ shows that by this definition of innovation, the rate of pharmaceutical innovation is not declining. In fact, since the 1962 regulatory requirement in the United States for manufacturers to establish evidence of safety and effectiveness, there has been an increase in the number of new products reaching the market. Furthermore, an analysis by Munos shows that the rate of drug approvals has been constant over the past 60 years with an upward trend from 1980-95 (culminating in 53 approvals in 1996). ${ }^{16}$ The argument that regulation has reduced pharmaceutical innovation is therefore unsubstantiated.

Although the number of new products reaching the market has not decreased with existing regulation, manufacturers argue that stricter market authorisation will lead to fewer new drug approvals at increasingly higher cost. ${ }^{17}$ The cost of developing new drugs has reportedly increased, as have total research and development expenditures, ${ }^{18}$ while the number of new drugs introduced to the market has increased moderately. ${ }^{19}$ However, there are disagreements regarding the research and development costs of a new drug ${ }^{20}$ with some research finding oft stated figures to be grossly overestimated. ${ }^{21}$ Total research and development expenditures may include promotional spending that is not directly tied to developing new products. ${ }^{22}$ Inflation adjustment often does not properly account for changes in the price of investment, and reported research and development figures sometimes do not account for changes in prices.

\section{Effects of requiring comparative evidence}

Without historical evidence to suggest that regulation leads to declines in innovation, what are the other potential outcomes of introducing higher evidence standards? Requiring comparative evidence at the time of market approval could have a number of advantages. In the current regulatory environment, relative benefits and harms of a new drug often emerge only after market entry, which may be too late to adequately meet the information needs of decision makers in clinical practice.

In addition, unlike regulatory agencies, payers need manufacturers to provide comparative evidence to support decisions for coverage and reimbursement. In some cases, this discrepancy in evidence requirements results in conflicting decisions by regulatory agencies and healthcare funders. For example, health technology assessment agencies such as the National Institute for Health and Clinical Excellence (NICE) in the United Kingdom, which makes decisions on value for money on behalf of the National Health Service, require comparative evidence to inform decisions on coverage and reimbursement. A lack of relevant head to head trial data was one of the reasons NICE cited for recommending against reimbursement of bevacizumab, cetuximab, and panitumumab, which were approved by the EMA for metastatic colorectal cancer. There is a need to align the evidence needs of regulatory bodies, country level payers, and health technology assessment agencies. ${ }^{23}$

Requirements for comparative evidence at the time of market approval could also encourage manufacturers to focus on therapeutic areas with limited treatment options or where comparators have poor efficacy or serious side effects, because drugs in those areas would face fewer obstacles to authorisation. There are indications that this is already

happening - manufacturers are increasingly evaluating their portfolios to identify the products likely to face the greatest scrutiny. ${ }^{24}$ These include product classes with numerous, similar alternative therapies such as biological treatments for rheumatoid arthritis and oral treatments for diabetes. Given that investment in active-comparator trials varies tremendously across therapeutic areas, standardising evidence requirements and making comparative evidence the default option could shift drug development towards areas where innovation has historically been lacking. ${ }^{25}$

Nonetheless, there are legitimate concerns regarding changes in evidence standards. Critically, judgments of efficacy are often based on surrogate outcome measures, not clinical endpoints, which can complicate the assessment of benefits and harms at the time of market entry. Even if comparative evidence for market approvals becomes the norm, the full effects of new treatments approved on evidence from surrogate endpoints may remain unknown until after marketing, as in the case for rosiglitazone and pioglitazone in type 2 diabetes.

Requiring manufacturers to generate comparative evidence could also lead to more costly and lengthy clinical trials, particularly if superiority claims are sought and multiple comparators are needed. To alleviate manufacturers' concerns, our proposal is to require evidence of similarity (equivalence or non-inferiority at a minimum) for all conditions for which an alternative treatment option exists. Given that only about $10 \%$ of new medicines that reach the market are deemed superior to existing alternatives ${ }^{26}$ requiring evidence of superiority could limit the number of therapeutically viable alternatives for a given condition and make it more difficult for clinicians to individualise treatment options. Nevertheless, others have proposed that for conditions with an existing generic treatment, 


\section{Milestones in US legislation on market authorisation ${ }^{14}$}

1906: Food and Drugs Act-prohibits interstate commerce in misbranded and adulterated drugs

1927: Regulatory functions pertaining to drugs are located under the Food, Drug, and Insecticide Administration (named Food and Drug Administration in 1930)

1938: The Federal Food, Drug, and Cosmetic (FDC) Act requires new drugs to be shown to be safe before marketing

1962: Kefauver-Harris Drug Amendments-requires drug manufacturers to provide FDA with evidence of safety as well as effectiveness of their products before marketing them

1966: Fair Packaging and Labeling Act-requires all consumer products in interstate commerce to be honestly and informatively labelled, with FDA enforcing provisions on drugs and medical devices

1970: FDA requires the first patient package insert, mandating manufacturers to provide patients with information about specific risks and benefits of drugs and devices

1976: Medical Device Amendments-requires manufacturers to register with FDA and follow quality control procedures to ensure safety and effectiveness of medical devices and diagnostic products

1983: Orphan Drug Act-enables FDA to promote research and marketing of drugs needed for treating rare diseases

1988: Prescription Drug Marketing Act-bans the diversion of prescription drugs from legitimate commercial channels

1992: Prescription Drug User Fee Act-requires manufacturers to pay fees for product applications and other services

1997: Food and Drug Administration Modernization Act-reauthorises the Prescription Drug User Fee Act of 1992. Provisions include measures to accelerate review of devices, regulate advertising of unapproved uses of approved drugs and devices, and regulate health claims for foods

manufacturers should demonstrate the superiority of the new drug over the next best option in terms of either greater efficacy or improved safety. ${ }^{27}$

\section{Conclusions}

A stricter regulatory environment for market access is likely to be opposed by manufacturers, who will claim that patients will suffer from fewer medicines reaching the market. However, there is no evidence that increased regulation limits the number of new drug approvals. Requiring comparative evidence at the time of market entry would ensure that patients, clinicians, and other healthcare decision makers such as payers and health technology assessment bodies are adequately informed about the relative merits of new treatments. Furthermore, changing the nature of regulation and raising the evidence standards at the time of licensing decisions could encourage manufacturers to concentrate on the development of new drugs in therapeutic areas with few or no alternatives. While formal regulation can take years to develop, supplementing regulation with scientific advice and guidance can steer manufacturers' interest and efforts into key research priorities and important technical issues.

Overall, the risks associated with making market entry stricter seem to be relatively modest, particularly when compared with the potential benefits.

Contributors and sources: $\mathrm{HN}, \mathrm{JC}$, and SV have written several articles on pharmaceutical policy and regulation in the European Union and the United States. HN, JC, SV, and AS have experience in pharmaceutical regulation at the market entry and pricing levels. KP has experience in health technology assessment through his role at the National Institute for Health and Clinical Excellence. The views expressed here do not necessarily reflect those of NICE. JC has extensive experience of European health systems through his involvement with the European Observatory on Health Systems and Policies. HN, JC, SV, AS, and KP devised the article. All authors developed the first draft and also contributed to subsequent drafts. All have read and agreed to the final version. $\mathrm{HN}$ is the guarantor.

Competing interests: All authors have completed the ICMJE unified disclosure form at www.icmje.org/coi_disclosure.pdf (available on request from the corresponding author) and declare no support from any organisation for the submitted work; no financial relationships with any organisation that might have an interest in the submitted work in the previous three years; and no other relationships or activities that could appear to have influenced the submitted work.
This article is part of an occasional series prepared in conjunction with the European Observatory on Health Systems and Policies (www. healthobservatory.eu).

Provenance and peer review: Not commissioned; externally peer reviewed.

1 Sorenson C, Naci H, Cylus J, Mossialos E. Evidence of comparative efficacy should have a formal role in European drug approvals. BMJ 2011;343:d4849.

2 IMAP. Pharmaceuticals and biotech industry global report-2011. www.imap.com/imap/ media/resources/IMAP_PharmaReport_8_272B8752E0FB3.pdf.

3 Alexander GC, O'Connor AB, Stafford RS. Enhancing prescription drug innovation and adoption. Ann Intern Med 2011:154:833-7.

4 ECORYS Research and Consulting. Competitiveness of the EU market and industry for pharmaceuticals. Vol 1. Welfare implications of regulation: final report. 2011. http://ec. europa.eu/enterprise/sectors/healthcare/files/docs/vol_1_welfare_implications_of_ regulation_en.pdf.

5 O'Connor AB. Building comparative efficacy and tolerability into the FDA approval process. JAMA 2010;303:979-80.

6 Garattini S, Bertele V. Efficacy, safety, and cost of new anticancer drugs. BMJ 2002;325:269-71.

7 Morgan SG, Bassett KL, Wright JM, Evans RG, Barer ML, Vaetano PA, et al. Breakthrough drugs and growth in expenditure on prescription drugs in Canada. BMJ 2005;331:815-6.

8 Stafford RS, Wagner TH, Lavori PW. New, but not improved? incorporating comparative-effectiveness information into FDA labeling. N Engl J Med 2009:361:1230-3.

9 Gottlieb S. The FDA should not mandate comparative-effectiveness trials. American Enterprise Institute for Public Policy Research, 2011.

10 Vernon JA. Examining the link between price regulation and pharmaceutical R\&D investment. Health Economics 2005;14:1-16.

11 House Energy and Commerce Committee. Health subcommittee examines FDA regulatory process. Press release, 7 July 2011. http://energycommerce.house.gov/news/PRArticle. aspx? NewsID=8782.

12 Economist Intelligence Unit. Reinventing biopharma: strategies for an evolving marketplace-the value challenge. 2012. www.quintiles.com/elements/media/white-papers/ thevaluechallange.pdf.

13 Carpenter D. Reputation and power: organizational image and pharmaceutical regulation at the FDA: Princeton, 2010.

14 US Food and Drug Administration. Significant dates in US food and drug law history. www.fda.gov/AboutFDA/WhatWeDo/History/Milestones/ucm128305.htm.

15 European Medicines Agency. Reflection paper on the need for active control in therapeutic areas where use of placebo is deemed ethical and one or more established medicines are available. 2010. www.ema.europa.eu/docs/en_GB/document_library/Scientific guideline/2011/01/WC500100710.pdf.

16 Munos B. Lessons from 60 years of pharmaceutical innovation. Nat Rev Drug Discov 2009;8:959-68.

17 Paul SM, Mytelka DS, Dunwiddie CT, Persinger CC, Munos BH, Lindborg SR, Schacht AL. How to improve R\&D productivity: the pharmaceutical industry's grand challenge. $\mathrm{Nat}$ Rev Drug Discov 2010;9:203-14

18 DiMasi JA, Hansen RW, Grabowski HG. The price of innovation: new estimates of drug development costs. $J$ Health Econ 2003:22:151-85.

19 Cockburn IM. Is the pharmaceutical industry in a productivity crisis? In: Innovation policy and the economy. National Bureau of Economic Research, 2007:1-32. www.nber.org/ chapters/c0032.

20 Angell M. The truth about the drug companies: how they deceive us and what to do about it. Random House Trade, 2005.

21 Light DW, Warburton R. Demythologizing the high costs of pharmaceutical research. BioSocieties 2011;6:34-50.

22 Gagnon M-A, Lexchin J. The Cost of pushing pills: a new estimate of pharmaceutical promotion expenditures in the United States. PLoS Med 2008;5:e1.

23 Eichler H-G, Bloechl-Daum B, Abadie E, Barnett D, Konig F, Pearson S. Relative efficacy of drugs: an emerging issue between regulatory agencies and third-party payers. Nat Rev Drug Discov 2010;9:277-91.

24 Carrier E, Pham H, Rich E. Comparative effectiveness research and innovation: policy options to foster medical advances. National Institute for Health Care Reform, 2010. 
25 Goldberg NH, Schneeweiss S, Kowal MK, Gagne JJ. Availability of comparative efficacy data at the time of drug approval in the United States. JAMA 2011;305:1786-9.

26 Van Luijn JC, Gribnau FW, Leufkens HG. Superior efficacy of new medicines? Eur J Clin Pan Luijn JC, Gribnau FW,

27 Gagne JJ, Choudhry NK. How many "me-too" drugs is too many? JAMA 2011;305:711-2.

\section{Accepted: 18 May 2012}

Cite this as: BMJ 2012;344:e4261

(c) BMJ Publishing Group Ltd 2012 


\section{Figure}

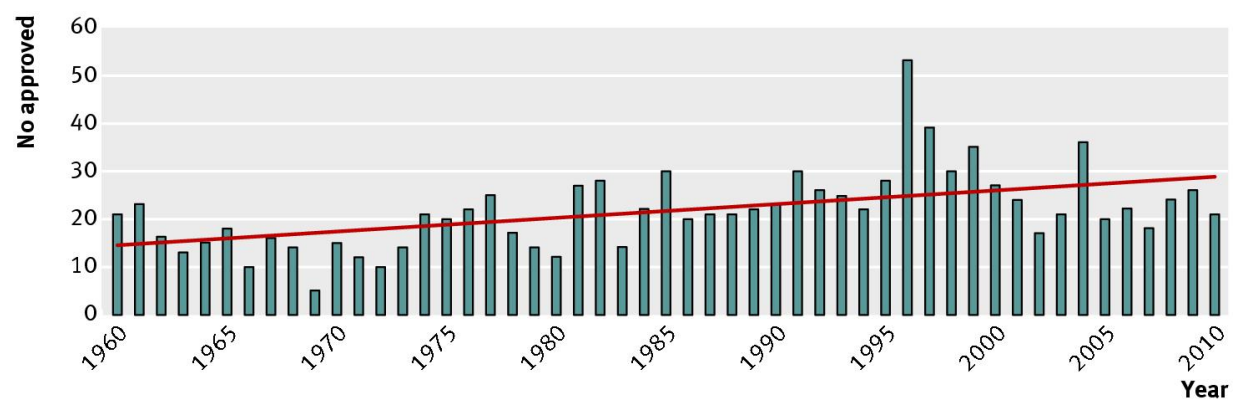

Fig 1 Number of new molecular entities approved in the United States, 1960-2010 